\title{
LA EDUCACIÓN TURÍSTICA EN EL CONTEXTO DE GEOPARQUE IMBABURA CASO \\ DE ESTUDIO: ESTUDIANTES DE NIVEL MEDIO DE LA UNIDAD EDUCATIVA LUIS LEORO FRANCO, IBARRA-ECUADOR
}

THE TOURIST EDUCATION IN THE CONTEXT OF IMBABURA GEOPARK CASE OF STUDY: MID-LEVEL STUDENTS OF THE EDUCATIONAL UNIT LUIS LEORO FRANCO, IBARRA-ECUADOR

Manuela Ángela Enríquez Hidalgo, Ing. Ingeniera en Turismo (Ecuador). Estudiante de Maestría en Turismo, mención Patrimonio y Turismo Comunitario: Universidad Técnica del Norte de la Universidad de Guayaquil, Ecuador. anghiee10@hotmail.es

MSc. Yoarnelys Vasallo Villalonga Máster en Gestión Turística mención Gestión Hotelera (Cuba). Docente investigadora de la Universidad Técnica del Norte de la Universidad de Guayaquil, Ecuador. yvasallo@utn.edu.ec

\section{ARTÍCULO DE INVESTIGACIÓN}

Recibido: 20 de agosto de 2019.

Aceptado: 25 de noviembre de 2019.

\section{RESUMEN}

Ecuador tiene un gran potencial turístico donde se destaca su patrimonio natural y cultural. La educación en temáticas acorde a esta área de estudio requiere de un proceso integrador que forme a los individuos en conocimientos y valores para que puedan enfrentar diferentes retos. Esta investigación se enfocó en fomentar la educación turística en estudiantes de nivel medio de la Unidad Educativa Luis Leoro Franco mediante el diseño de una guía con temáticas turísticas de importancia en el contexto de Geoparque Imbabura para el uso de los docentes de sextos Años de Educación General Básica. Se plantearon tres objetivos específicos: identificar las materias, contenidos y metodologías respecto a la educación turística existentes en los planes de estudios actuales de los sextos años de EGB; determinar la disposición de la comunidad educativa para involucrarse en el tema de educación turística y diseñar una guía con temáticas turísticas de importancia en el contexto del Geoparque Imbabura para el uso de los docentes de sextos Años de EGB. La metodología desarrollada, según la naturaleza 
de la información tiene un enfoque cualitativo con un alcance descriptivo. Por otro lado, es una investigación documental y de campo; se emplea el método analítico-sintético y se han aplicado algunas técnicas de recopilación de información como: fichas técnicas, entrevista grupal (focus group) y encuestas; teniendo en cuenta a todos los actores de la comunidad educativa: autoridades, docentes, padres de familia y estudiantes.

Palabras clave: geoparque; educación; turismo; Imbabura.

\section{ABSTRACT}

Ecuador has great tourist potential where its natural and cultural heritage stands out. Education in topics according to this area of study requires an integrative process that trains individuals in knowledges and values so that they can face different challenges. so that they can face different challenges. This research focused on promoting tourism education in middle-level students of the Luis Leoro Franco Educational Unit through the design of a guide with tourist themes of importance in the context of Imbabura Geopark for the use of teachers of sixth years of Basic General Education. Three specific objectives were raised: Identify the subjects, contents and methodologies with respect to tourism education existing in the current curricula of the sixth years of EGB. In addition, determine the willingness of the educational community to get involved in the topic of tourism education and finally: Design a guide with important tourist themes in the context of Imbabura Geopark for the use of teachers of sixth years of EGB. The methodology developed, according to the nature of information has a qualitative approach with a descriptive scope. On the other hand, it is a documentary and field investigation; The analytical-synthetic method is used and some information collection techniques have been applied such as: technical sheets, group interview (focus group) and surveys; taking into account all the actors of the educational community: authorities, teachers, parents and students.

Keywords: geopark; education, tourism; Imbabura

\section{INTRODUCCIÓN}

La educación es un proceso integrador en el que convergen diferentes elementos capaces de generar aprendizajes y experiencias en los seres humanos, mediante el uso de metodologías y técnicas pedagógicas. Se encuentra presente en todas las áreas del conocimiento y en el 
turismo desempeña un papel fundamental ya que la relación del binomio turismo-educación y educación-turismo, se centran en dos vertientes: la formación turística y los contenidos educativos del turismo. Los trabajos sobre educación turística señalan que es vista como elemento formador del individuo, generando actitudes y valores orientados a situaciones de aceptación, respeto y convivencia social (Tamayo \& Peñaloza, 2005).

El 17 de abril del año 2019 la provincia de Imbabura fue declarada por la UNESCO como Geoparque, convirtiéndose en el primero del Ecuador. Con esta designación se presentan nuevos retos para la provincia ya que no se trata solamente de tener atractivos naturales, culturales y paisajísticos; al contrario, se debe iniciar un proceso de visibilización y puesta en valor de todos los sitios, involucrando a toda la comunidad local en este proceso. Al ingresar a la Red de 147 Geoparques en 41 países se deben gestionar estrategias de desarrollo sustentable, basadas en el uso del patrimonio como herramienta de desarrollo social y comunitario.

Los geoparques son territorios bien delimitados, que comprenden uno o varios sitios de importancia científica, no sólo geológica sino arqueológica, ecológica, histórica y cultural, que corresponden a una estrategia holística de gestión (Red Mundial de Geoparques, 2011). Estos espacios promueven un desarrollo integral, enlazando diferentes enfoques: construcción social, patrimonio, conservación ambiental y también se encuentran articulado a una dimensión educativa, orientada a la interpretación, comunicación y conservación.

Las instituciones educativas como agentes transmisores y difusores de conocimiento desempeñan un papel fundamental en la sociedad, impulsan el desarrollo local a través de la formación en competencias, habilidades y destrezas en el talento humano. Existe una relación entre educación y turismo, lo cual se evidencia en las dimensiones que comprende Geoparque Imbabura como: geo educación, enmarcada en aprovechar racionalmente el potencial de territorio y contribuir con acciones para su conservación. Geoturismo se encuentra centrado en destacar el patrimonio geológico, la geodiversidad y biodiversidad del territorio y la dimensión de geo conservación del patrimonio geológico, natural, antropológico, histórico y cultural del territorio imbabureño. Según Farsani (2012) el geoturismo se define como el turismo que sustenta o contribuye a mejorar las características geográficas de un lugar, ya sea el medio ambiente, patrimonio histórico, aspectos estéticos, culturales o el bienestar de sus habitantes. Por otro lado, geo conservación es el conjunto de técnicas y medidas encaminadas a asegurar la conservación (incluyendo la rehabilitación) del patrimonio geológico y de la geodiversidad, basada en el análisis de sus valores intrínsecos, su vulnerabilidad y en el riesgo de degradación (Ramón y Fernández, 2016). 
El Programa Mundial de Cultura de la UNESCO tiene como misión proteger el patrimonio, promoviendo el papel central de la cultura y la creatividad como medio para lograr el desarrollo sostenible y fomentar la paz. Entre los objetivos de desarrollo sostenible de esta organización se encuentran algunas metas: Para 2030, garantizar que todos los alumnos adquieran los conocimientos teóricos y prácticos mediante la educación y la adopción de estilos de vida sostenibles, los derechos humanos, la igualdad entre los géneros, la promoción de una cultura de paz y no violencia, la ciudadanía mundial y la valoración de la diversidad cultural y de la contribución de la cultura al desarrollo sostenible, entre otros medios. Desde 1972 en la Convención sobre la protección del patrimonio mundial, cultural y natural, se hace referencia a la importancia de la educación patrimonial; estableciendo en el artículo 27, la importancia de los programas de educación y de información, donde se debe hacer todo lo posible por estimular en los pueblos el respeto y el aprecio del patrimonio cultural y natural.

A nivel nacional, la Constitución del Ecuador 2008, en el artículo 26 establece que la educación es un derecho de las personas a lo largo de su vida y un deber ineludible e inexcusable del Estado. Constituye un área prioritaria de la política pública y de la inversión estatal, garantía de la igualdad e inclusión social y condición indispensable para el buen vivir. Las personas, las familias y la sociedad tienen el derecho y la responsabilidad de participar en el proceso educativo. De la misma forma en el artículo 27, señala que la educación debe estar centrada en el ser humano y garantizará su desarrollo holístico, en el marco del respeto a los derechos humanos, al medio ambiente sustentable y a la democracia. Por otro lado, la Ley Orgánica de Cultura vigente desde el año 2016, en su artículo cuatro, referente a los principios establece: Integralidad y complementariedad del sector cultural que implica la interrelación con educación, comunicación, ambiente, salud, inclusión social, ciencia, tecnología, turismo, agricultura, economía y producción, entre otros ámbitos y sistemas. Además, La ley Orgánica de Educación Intercultural (LOEI) del año 2019, en el artículo dos, referente a principios establece lo siguiente: literal n) Comunidad de aprendizaje. - La educación tiene entre sus conceptos aquel que reconoce a la sociedad como un ente que aprende y enseña y se fundamenta en la comunidad de aprendizaje entre docentes y educandos, considerada como espacios de diálogo social e intercultural e intercambio de aprendizajes y saberes. literal u) Investigación, construcción y desarrollo permanente de conocimientos como garantía del fomento de la creatividad y de la producción de conocimientos, promoción de la investigación y la experimentación para la innovación educativa y la formación científica. Además, el artículo tres, referente a los fines de la educación en el literal k establece el fomento del conocimiento, respeto, valoración, rescate, preservación y promoción del patrimonio natural y cultural tangible e intangible. 
El Ministerio de Educación de Ecuador como ente rector, establece los nuevos currículos 2019-2020 de Educación General Básica para los subniveles de Preparatoria, Elemental, Media y Superior y, para el nivel de Bachillerato General Unificado con sus respectivas cargas horarias, mismo que es de aplicación obligatoria en todo el Sistema Educativo Nacional; a partir de septiembre de 2016 en los establecimientos escolares con régimen Sierra y Costa. El sistema educativo ecuatoriano ha atravesado por diferentes etapas desde 1970. Actualmente se ha hecho un reajuste curricular expedido en 2016. En dicho documento legal se divide el sistema educativo ecuatoriano en los siguientes niveles:

- Educación Inicial

- Educación General Básica (EGB) misma que comprende cuatro subniveles:

- Preparatoria: primer grado, ofertada a estudiantes con cinco años.

- Básica Elemental: segundo, tercer y cuarto grado, estudiantes de seis a ocho años de edad.

- Básica Media: quinto, sexto y séptimo grado, estudiantes de nueve a once años.

- Básica Superior: octavo, noveno y décimo grado, estudiantes de doce a catorce años.

- Bachillerato

La presente investigación se concentra en la Educación General Básica, tomando en cuenta a estudiantes de sexto grado, conjuntamente con los diferentes actores de toda la unidad educativa: autoridades, docentes y padres de familia.

Ante esta situación el problema de investigación que se plantea es: ¿Cómo fomentar la educación turística en estudiantes de nivel medio de la Unidad Educativa Luis Leoro Franco en el contexto Geoparque Imbabura? La pertinencia de la investigación radica en la importancia de iniciar un proceso de educación turística desde los más pequeños, donde se incorpore a las mallas curriculares del plan de estudio de los estudiantes de sextos años de EGB contenidos referentes a cultura turística, aspectos históricos, geográficos, patrimonio natural y cultural; ya que ellos pueden ser replicadores de la información y de esta manera toda la comunidad logrará adquirir conocimientos elementales sobre el patrimonio que tiene la provincia. Mediante el diseño de una guía con temáticas turísticas de importancia en contexto de Geoparque Imbabura para el uso de los docentes de sextos años de EGB se podrá formar educación turística en los estudiantes, y contribuir al fomento de cultura turística en la población local. Para el desarrollo de la investigación los objetivos planteados son: identificar las materias, contenidos y metodologías respecto a la educación turística existentes 
en los planes de estudios actuales de los sextos años de EGB; determinar la disposición de la comunidad educativa para involucrarse en el tema de educación turística en el contexto Geoparque Imbabura y diseñar una guía con temáticas turísticas de importancia en el contexto de Geoparque Imbabura para el uso de los docentes de sextos Años de EGB.

Colom y Brown (1993) han denominado áreas de la Pedagogía del turismo las siguientes:

- Educación para la comprensión internacional, donde el turismo es una estrategia para educar en la paz, en la solidaridad, en la comprensión entre los pueblos y donde el turismo aporta una ideología internacionalista a través de los valores patrocinados por los sistemas escolares y educativos y sus prácticas en el ámbito escolar.

- Educación para el interculturalismo, como consecuencia de una educación para la solidaridad y comprensión internacional, el turismo es una estrategia para la comprensión y aceptación de otras culturas.

- Educación para el ocio y el tiempo libre, donde el hecho turístico tiene mayor relación con lo educativo a través del turismo escolar en todos los niveles educativos, así como otras actividades no formales que se generan a nivel nacional e internacional, como campamentos juveniles, campos de trabajo, encuentros internacionales.

- Educación ambiental, que por el impacto directo e indirecto que ocasiona el desarrollo turístico en el medio ambiente, de tal manera que el turismo se convierte en una estrategia de educación y formación masiva.

Según Cazares, Aranguren y Moncada (2017) en su artículo de investigación titulado: Educación para el turismo sustentable en la escuela ecuatoriana. Una propuesta para la parroquia La Libertad, Cantón Espejo, provincia del Carchi; se abordan temas vinculados al turismo sustentable que hacen los docentes en la institución con la finalidad de proponer un diseño instruccional. El desarrollo de la investigación se hace en tres fases: con el análisis de los programas de estudio para diagnosticar contenidos referentes a patrimonio natural local, desarrollo sustentable y turismo, además se aborda el eje educativo desarrollado por los docentes. Los autores concluyen que los temas de turismo y sustentabilidad son poco considerados en los contenidos de los programas del nivel de Educación General Básica de segundo a séptimo grado. De la misma forma como propuesta el diseño instruccional está constituido con un módulo para docentes y un video educativo, mismos que proponen un conjunto de estrategias didácticas.

Por otro lado, Díaz y Machado (2016), en su investigación titulada: La formación en cultura turística en instituciones educativas: un aporte del programa "colegios amigos del turismo" en 
Colombia; analizan algunas características que identifican cómo las instituciones educativas pueden desarrollar la cultura turística en los estudiantes desde la formación en las áreas de ciencias sociales y ciencias naturales. De la misma manera abordan temáticas importantes vinculadas en el desarrollo de destrezas en estudiantes, analizando la normativa legal y establecen que: si desde la escuela se concientiza a los estudiantes sobre la importancia de su destino, generarán mayor compromiso en cuanto al uso y la conservación tanto de los recursos naturales como de los culturales. Esta sensibilización y tal apropiación deben hacerse a partir de actividades pedagógicas programadas por las áreas y que tengan relación con la cultura turística. Los resultados según señalan las autoras permitieron identificar las actividades que fortalecen la cultura turística con base en la dinámica de cada institución.

\section{REVISIÓN TEÓRICA}

Imbabura, conocida como la provincia de los lagos, se encuentra ubicada en la sierra norte de Ecuador. Su capital es Ibarra, limita al norte con la provincia del Carchi, al sur con Pichincha, al este con Sucumbíos y al oeste con Esmeraldas. Posee una extensión de 4559 km2 y 398.244 habitantes. Está conformada por seis cantones: Ibarra, Otavalo, Cotacachi, Antonio Ante, San Miguel de Urcuquí y Pimampiro; 36 parroquias rurales y seis urbanas. Imbabura tiene condiciones geográficas que determinan una gran diversidad de ecosistemas con climas que incluyen el cálido seco, cálido húmedo, templado y frío. Esta provincia posee diversidad geológica, étnica y cultural, asimismo varias tradiciones y cosmovisiones de los pueblos ancestrales Cayambis, Caranquis, Otavalos, Zuletas, Natabuelas, Afro, Awas y Montubio. El 17 de abril del 2019 fue declarada por la UNESCO como Geoparque Mundial debido a su patrimonio geológico, espacios de interés científico, singularidad y representatividad. Se han identificado 56 geositios entre valles, cascadas, lagunas, termas, montañas y páramos, mismos que formaban parte del proyecto, actualmente la prefectura de la provincia se encuentra realizando un análisis para definir aquellos sitios que pueden considerarse como turísticos. La ciudad de Ibarra conocida como ciudad Blanca a la que siempre se vuelve es la cabecera del cantón Ibarra, capital de la provincia de Imbabura. Tiene cinco parroquias urbanas y seis rurales; tiene una superficie de $1162 \mathrm{~km} 2$, y 181.175 habitantes (INEC, 2010). La Institución Educativa La institución educativa señalada como caso de estudio para la investigación se encuentra ubicada en la zona urbana de la ciudad de Ibarra, parroquia San Francisco, en la calle Juan Francisco Bonilla 12-29 y Antonio Cordero. Su tipo de educación es regular, de sostenimiento fiscal e hispana. La Escuela "General Luis 
Leoro Franco" fue creada el 30 de enero de 1975, y que por resolución ministerial con fecha 23 de febrero de 2015 manifiesta la fusión de las instituciones EGB Leoro Franco, EGB Aída León, EGB Víctor Manuel Peñaherrera, y CEI Albertina Franco De Leoro, motivo por el cual el 31 de mayo de 2015 cambia su denominación a Unidad Educativa "Luis Leoro Franco". La institución educativa cuenta con un personal de 83 docentes, 6 administrativos y 4 auxiliares de servicio bajo el Código de Trabajo. Oferta educación inicial, educación básica y bachillerato con un enfoque constructivista y humanístico a 1865 estudiantes distribuidos en 4 ambientes, en las jornadas matutina y vespertina bajo la modalidad presencial. Educa a estudiantes que en su mayoría provienen del sector rural de la ciudad. Existen mestizos, afroecuatorianos e indígenas y además recibe una importante población de migrantes de los países vecinos. (Junta Académica, 2019).

La investigación a desarrollar según la naturaleza de información tiene un enfoque cualitativo de alcance descriptivo ya que se realiza una revisión bibliográfica para identificar los contenidos existentes en mallas curriculares para el diseño de una guía con temáticas turísticas. Con la finalidad de identificar las materias, contenidos y metodologías respecto a la educación turística existentes en los planes de estudios actuales de los sextos años de EGB, se realiza una investigación documental, haciendo una revisión de documentos como: la malla curricular 2019-2020 del Ministerio de Educación del Ecuador, además del Plan Curricular Anual (PCA) y la Planificación Micro curricular de Unidad Didáctica manejados por la institución (PUD). Para determinar la disposición de la comunidad educativa para involucrarse en el tema de educación turística en el contexto Geoparque Imbabura, se realiza una investigación de campo, ya que se aplica una entrevista grupal (focus group) y encuestas a los actores de interés de la Unidad Educativa Luis Leoro Franco.

Por otro lado, se realiza una revisión bibliográfica de documentos como: tesis, páginas web y mallas curriculares para diseñar una guía con temáticas turísticas de importancia en el contexto de Geoparque Imbabura para el uso de los docentes de sextos Años de Educación General Básica. El método de investigación aplicado para los objetivos uno y tres es el analítico-sintético: ya que permite el análisis de la información recopilada referente a las temáticas tratadas en cada asignatura del plan de estudios de los sextos años de Educación General Básica. Posteriormente, se sintetiza los datos obtenidos para generar ideas claras de los posibles contenidos en temática de educación turística que podrían ser incorporados en la malla curricular. Debido a la naturaleza y pertinencia de la investigación se ha seleccionado como grupos de estudio a los siguientes actores: autoridades, docentes, padres de familia y estudiantes de los sextos años de educación media de esta institución con la 
finalidad de analizar su disposición para involucrarse en el tema de educación turística. Se aplica un censo, pues se ha seleccionado el $100 \%$ de la población conformada por 126 estudiantes, 126 padres de familia y 13 docentes que pertenecen al nivel de básica media: quintos, sextos y séptimos años.

Para responder al primer objetivo específico se elabora una ficha técnica en la que se detallan las unidades didácticas, contenidos y metodologías presentes respecto a la educación turística existentes en el plan de estudios actuales de los sextos años de EGB en las siguientes áreas: Lengua y Literatura, Matemática, Estudios Sociales, Ciencias Naturales. EI Ministerio de Educación plantea el ciclo de aprendizaje ERCA que es practicado por la institución. Este consiste en un aprendizaje con enfoque participativo. El ciclo tiene cuatro momentos: experiencia, reflexión, conceptualización y aplicación, es un método general que permite enseñar a niños, niñas y adolescentes de acuerdo a sus etapas de desarrollo cognitivo, afectivo, social, lenguaje, favoreciendo el desarrollo integral del mismo, además permite la solución de problemas. Según la Planificación curricular institucional (PCI), la metodología en la institución educativa propicia la construcción de conocimientos tomando en cuenta ritmos y estilos de aprendizaje, relacionándolos con los métodos del saber, acompañados de actividades flexibles que le permitan el éxito del proceso enseñanzaaprendizaje, es decir la obtención de aprendizajes significativos, necesarios para que los estudiantes sean capaces de tomar decisiones, hacer sugerencias, ser participativos y promover el trabajo en equipo, llegar a conclusiones, analizar y aplicar el resultado de lo aprendido en una situación práctica, dando importancia a su parte genética, psicológica, biológica, social y cultural (PCI, 2018).

Cuadro 1. Áreas y metodologías utilizadas por la Unidad Educativa Luis Leoro Franco según su PCl.

\begin{tabular}{ll}
\hline Áreas & Metodologías \\
\hline \multirow{3}{*}{$\begin{array}{l}\text { Lengua y } \\
\text { Literatura }\end{array}$} & Método viso-audio-motor-gnósico (visualización, audición, audición, \\
& pronunciación, conocimiento y fase motora) \\
& Método Deductivo \\
& Método Inductivo \\
\hline & Método Heurístico \\
& Etapas: Presentación del problema, exploración experimental, presentación de \\
& informes, abstracción, generalización. \\
& Método Deductivo \\
& Método Inductivo \\
& Método de Simulación y Juegos \\
& Etapas: preparación del ambiente, ejecución, evaluación. \\
\hline
\end{tabular}




\begin{tabular}{cl}
\hline & Método de Investigación: \\
& Etapas: definición de la situación problemática, formulación de soluciones, \\
Estudios Sociales & búsqueda de información, comprobación, análisis de los resultados. \\
& Método de Observación directa \\
& Método de Observación Indirecta \\
\hline Ciencias & Método Experimental \\
Maturales & Librodo Científico \\
\hline
\end{tabular}

Fuente: (PCl, 2018).

Cuadro 2. Unidades didácticas y contenidos del área de Lengua y Literatura

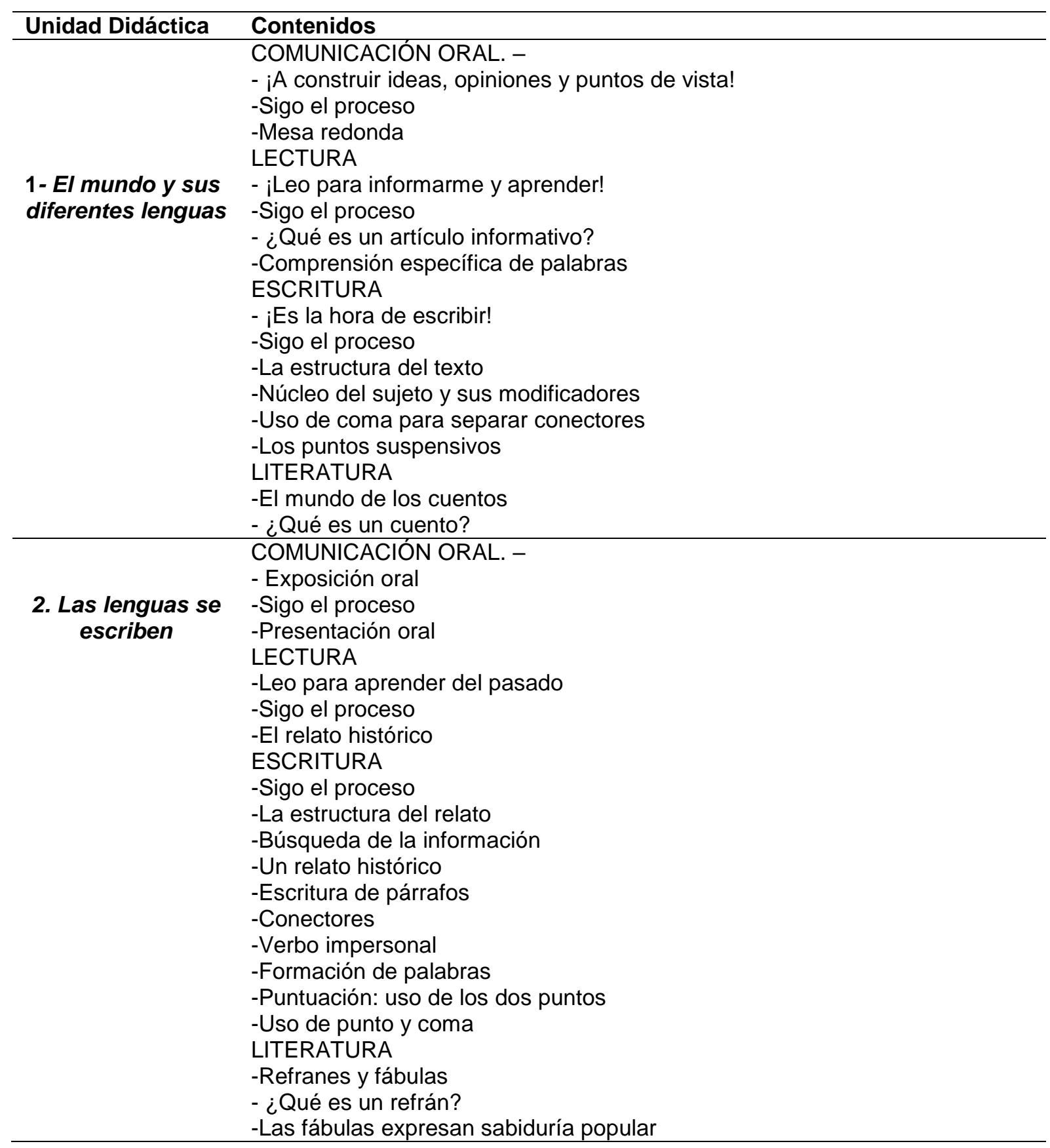




\begin{tabular}{|c|c|}
\hline $\begin{array}{c}\text { 3- Las funciones } \\
\text { del lenguaje }\end{array}$ & $\begin{array}{l}\text { COMUNICACIÓN ORAL. - } \\
\text { - Las cosas que hacemos con las palabras } \\
\text { LECTURA } \\
\text {-Leo y desarrollo mi pensamiento crítico } \\
\text {-Sigo el proceso } \\
\text { - ¿Qué es un discurso? } \\
\text { ESCRITURA } \\
\text {-Aprendo a resumir } \\
\text { - ¿Qué es un resumen? } \\
\text {-Sigo el proceso } \\
\text {-El verbo } \\
\text {-Accidentes del verbo } \\
\text {-Aplico una estrategia para resumir } \\
\text { LITERATURA } \\
\text {-Disfruto de la literatura ecuatoriana }\end{array}$ \\
\hline $\begin{array}{l}\text { 4. Los textos } \\
\text { tienen una } \\
\text { intención } \\
\text { comunicativa }\end{array}$ & $\begin{array}{l}\text { COMUNICACIÓN ORAL. - } \\
\text { - ¿Quiénes cambian la historia? } \\
\text {-Sigo el proceso } \\
\text { LECTURA } \\
\text {-Leo y desarrollo mi pensamiento crítico } \\
\text {-Sigo el proceso } \\
\text { - ¿Qué es un discurso? } \\
\text { ESCRITURA } \\
\text {-Campaña contra la violencia } \\
\text {-Sigo el proceso } \\
\text { - ¿Qué es un afiche? } \\
\text {-Grados del adjetivo } \\
\text {-Ortografía: Uso de la “j” } \\
\text { LITERATURA } \\
\text {-La literatura pinta la realidad }\end{array}$ \\
\hline
\end{tabular}

Fuente: (PCI, 2018).

Cuadro 3. Unidades didácticas y contenidos del área de Matemática

\begin{tabular}{cl}
\hline Unidad Didáctica & Contenidos \\
\hline & -Lectura y escritura de números naturales \\
1- Organizados & -Números primos y números compuestos \\
procedemos & - \\
mejor & -Los elementositud de la circunferencia \\
\hline & -Plano cartesiano con números decimales \\
& -Múltiplos \\
& -Divisores \\
2. Mi salud es & -Criterios de divisibilidad por 2, 4, 5 y 10 \\
Importante & -Criterios de divisibilidad por 3, 6, 7 y 9 \\
& -Factores primos \\
& -Área de paralelogramos y trapecios \\
& -Submúltiplos y múltiplos del metro cuadrado \\
\hline 3- Ciudadanía, & -Plano cartesiano con fracciones \\
democracia y & -Máximo común divisor (mcd) y mínimo común múltiplo (mcm) \\
participación & -Fracciones impropias, números mixtos \\
social & -Relación de orden entre fracciones \\
& -Ángulos y el sistema sexagesimal \\
& -Triángulos \\
& -Área de triángulos \\
\hline
\end{tabular}

ISSN: 1390-9320, Edición Especial, diciembre 2019 


\begin{tabular}{|c|c|}
\hline $\begin{array}{c}\text { 4. La } \\
\text { Interculturalidad } \\
\text { enriquece a } \\
\text { nuestro país }\end{array}$ & $\begin{array}{l}\text {-Adiciones y sustracciones con fracciones homogéneas } \\
\text {-Adiciones y sustracciones con fracciones heterogéneas } \\
\text {-Problemas de fracciones con suma y resta } \\
\text {-Décimas- centésimas y milésimas } \\
\text {-Sucesiones con sumas y restas } \\
\text {-Kilogramo, gramo y medidas de peso de la localidad } \\
\text {-Tablas estadísticas }\end{array}$ \\
\hline $\begin{array}{l}\text { 5. Mi Ecuador } \\
\text { biodiverso }\end{array}$ & $\begin{array}{l}\text {-Producto de un número decimal por 10, } 100 \text { y } 1000 \\
\text {-Divisiones con números decimales para 10, } 100 \text { y } 1000 \\
\text {-División entre dos números naturales } \\
\text {-Divisiones entre números naturales y decimales } \\
\text {-Reglas de redondeo } \\
\text {-Proporcionalidad directa } \\
\text {-Fracciones y divisiones a porcentajes } \\
\text {-Submúltiplos y múltiplos del metro cúbico } \\
\text {-Media, mediana y moda }\end{array}$ \\
\hline $\begin{array}{l}\text { 6. Respeto a la } \\
\text { diversidad de } \\
\text { identidades, } \\
\text { necesidades y } \\
\text { capacidades }\end{array}$ & $\begin{array}{l}\text {-La Potenciación } \\
\text {-Potencias con exponente } 2 \text { y } 3 \\
\text {-La radicación } \\
\text {-Operaciones combinadas con números decimales } \\
\text {-Polígonos regulares } \\
\text {-Perímetro de polígonos } \\
\text {-Sucesos aleatorios y cálculo de probabilidades }\end{array}$ \\
\hline
\end{tabular}

Fuente: (PCl, 2018).

Cuadro 4. Unidades didácticas y contenidos del área de Estudios Sociales

\begin{tabular}{|c|c|}
\hline Unidad Didáctica & Contenidos \\
\hline $\begin{array}{l}\text { 1- Ecuador: } \\
\text { Primer período } \\
\text { republicano A }\end{array}$ & $\begin{array}{l}\text {-Espacio y población a inicios de la República } \\
\text {-La vida rural } \\
\text {-Las ciudades en el siglo XIX } \\
\text {-El Ecuador regionalizado } \\
\text {-Educación y cultura } \\
\text {-La vida cotidiana (La pobreza y desunión de Ecuador naciente) }\end{array}$ \\
\hline $\begin{array}{l}\text { 2. Ecuador: } \\
\text { Primer período } \\
\text { republicano B }\end{array}$ & $\begin{array}{l}\text {-Predominio oligárquico } \\
\text {-Fundación de la República } \\
\text {-La revolución marcista y su secuencia } \\
\text {-Consolidación del Estado } \\
\text {-Final del siglo XIX } \\
\text {-La cultura a fines del siglo XIX (Acciones para consolidar la unidad nacional) }\end{array}$ \\
\hline $\begin{array}{l}\text { 3- Ecuador: } \\
\text { Segundo período } \\
\text { republicano } A\end{array}$ & $\begin{array}{l}\text {-El auge cacaotero } \\
\text { - La Revolución Liberal } \\
\text {-Características del Estado laico } \\
\text {-Cambios en la sociedad ecuatoriana } \\
\text {-Predominio plutocrático (Resistencia popular a la plutocracia) }\end{array}$ \\
\hline $\begin{array}{l}\text { 4. Ecuador: } \\
\text { Segundo período } \\
\text { republicano } B\end{array}$ & $\begin{array}{l}\text {-Crisis económica de los veinte a los cuarenta } \\
\text {-La insurgencia social } \\
\text {-Política, cultura y "realismo social" } \\
\text {-La vida cotidiana } \\
\text {-Recesión e inestabilidad } \\
\text {-La desmembración territorial } \\
\text {-Una etapa de estabilidad (Avances de la educación y los derechos políticos) }\end{array}$ \\
\hline $\begin{array}{l}\text { 5. Origen y } \\
\text { diversidad en la } \\
\text { población } \\
\text { ecuatoriana }\end{array}$ & $\begin{array}{l}\text {-Las diversidades de nuestro país } \\
\text { - ¿Cómo se formó la población del Ecuador? (La diversidad de la población } \\
\text { ecuatoriana) }\end{array}$ \\
\hline
\end{tabular}

ISSN: 1390-9320, Edición Especial, diciembre 2019 


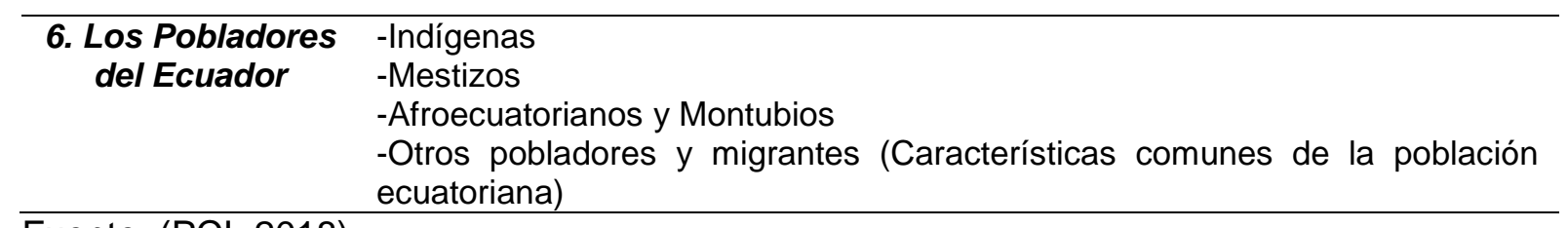

Fuente: (PCl, 2018).

Cuadro 5. Unidades didácticas y contenidos del área de Ciencias Naturales

\begin{tabular}{|c|c|}
\hline Unidad Didáctica & Contenidos \\
\hline 1- Vida Natural & $\begin{array}{l}\text {-Los animales vertebrados (mamíferos-aves-reptiles-anfibios-peces) } \\
\text {-Los animales invertebrados (anélidos-artrópodos-moluscos-Cnidarios- } \\
\text { equinodermos) } \\
\text {-Las plantas (plantas sin flor-plantas con flor) }\end{array}$ \\
\hline $\begin{array}{l}\text { 2. Ser humano y } \\
\text { salud }\end{array}$ & $\begin{array}{l}\text {-De la célula al ser humano } \\
\text {-El cuerpo humano y las funciones vitales (funciones vitales) } \\
\text {-La Salud (Las Enfermedades infecciosas- las enfermedades no infecciosas) } \\
\text {-Fases de la función de relación } \\
\text {-Los Órganos de los sentidos } \\
\text {-El sistema nervioso } \\
\text {-El aparato locomotor (el sistema esquelético) } \\
\text {-El sistema muscular } \\
\text {-El movimiento } \\
\text {-Hábitos saludables }\end{array}$ \\
\hline $\begin{array}{l}\text { 3- Diversidad } \\
\text { Biológica }\end{array}$ & $\begin{array}{l}\text {-Tiempo atmosférico y clima } \\
\text {-Fenómenos meteorológicos } \\
\text {-Climas y paisajes del mundo } \\
\text {-Clima en Ecuador } \\
\text {-El climograma (elaboración del climograma) } \\
\text {-Interpretación del climograma }\end{array}$ \\
\hline $\begin{array}{l}\text { 4. Hidrósfera y } \\
\text { Biósfera }\end{array}$ & $\begin{array}{l}\text {-La tierra (las capas de la tierra) } \\
\text {-El planeta Tierra y el agua (aguas oceánicas: mares y océanos-aguas } \\
\text { continentales-la biósfera y sus hábitats-Biósfera } \\
\text {-Los ecosistemas (cadenas y redes tróficas) } \\
\text {-Los organismos productores: las plantas (la célula vegetal y la fotosíntesis) } \\
\text {-Tipos de ecosistemas } \\
\text {-Conservación de los ecosistemas } \\
\text {-Desastres naturales (consecuencias de las catástrofes naturales) }\end{array}$ \\
\hline $\begin{array}{l}\text { 5. Transformación } \\
\text { de la Materia y } \\
\text { energía }\end{array}$ & $\begin{array}{l}\text {-Propiedades de la materia (propiedades generales-propiedades } \\
\text { características) } \\
\text {-Estados de la materia (estados sólido-líquido y gaseoso) } \\
\text {-Cambios en la materia (cambios físicos-cambios de estado-cambios } \\
\text { químicos) } \\
\text {-La clasificación de la materia } \\
\text {-Materia y materiales } \\
\text {-La energía y sus formas } \\
\text {-Los efectos de la energía } \\
\text {-Fuentes de energía (el uso de la energía) }\end{array}$ \\
\hline $\begin{array}{l}\text { 6. Fuerza, } \\
\text { electricidad } y \\
\text { magnetismo }\end{array}$ & $\begin{array}{l}\text {-Las fuerzas y sus efectos } \\
\text {-Combinación de las fuerzas } \\
\text {-Las máquinas (máquinas simples- máquinas compuestas) } \\
\text {-La energía eléctrica } \\
\text {-Circuitos eléctricos } \\
\text {-El magnetismo (Magnetismo terrestre) } \\
\text {-Electricidad y magnetismo (el electroimán) }\end{array}$ \\
\hline
\end{tabular}

Fuente: (PCl, 2018).

ISSN: 1390-9320, Edición Especial, diciembre 2019 
Para dar cumplimiento al objetivo número dos, se ha realizado una entrevista grupal (focus group) a docentes y autoridades de la Unidad Educativa, grupo conformado por trece personas. Se plantearon diez interrogantes en torno a la temática de Geoparque y la manera en que se abordan temas turísticos en las mallas curriculares de la institución.

Los resultados de la primera pregunta referente al conocimiento acerca de geoparque Imbabura muestran que los docentes no tienen ideas claras referente a la temática, algunos asocian el término con educación, tradiciones, pisos climáticos y diversidad cultural, dadas las características existentes en la provincia. En la pregunta dos, respecto a la dimensión educativa de geoparque los docentes señalan que en la institución se han abordado en las cuatro materias básicas de manera integradora temas referentes al cuidado del ambiente, flora, fauna, historia de los sitios a nivel local y provincial. Referente al diseño de una guía con contenidos turísticos como soporte didáctico, los docentes muestran una actitud favorable, pues manifiestan que incluso ellos desconocen de conceptualizaciones o herramientas para abordar el tema. De la misma forma, la educación es fundamental para poder fomentar la importancia de esta declaratoria en todos los actores de la comunidad educativa.

La pregunta cuatro en torno a las materias apropiadas para abordar contenidos turísticos en la malla educativa son ciencias naturales y estudios sociales, tratando datos geográficos e históricos. La siguiente interrogante surge en relación a que los contenidos en las mallas curriculares se encuentran establecidas, pero se pueden incluir trabajos autónomos donde se ponga en valor el patrimonio natural y cultural, inclusive rescatando leyendas. Las personas participantes en el focus group, consideran que la manera ideal para aprender turismo es en el campo más que en la teoría, hacerle partícipe al estudiante de experiencias vivenciales, para que estos visiten los sitios, además mostrarles la manera en la que ellos pueden aportar como ciudadanos y cómo deben cuidar cada lugar. Los docentes manifiestan en la pregunta sexta que se debe iniciar un proceso integrador como provincia con aliados estratégicos desde el Distrito Zonal, MINTUR y Ministerio de Educación para que todas las instituciones educativas se involucren, ya que de cierto modo la mayoría de giras de observación se realizan a zonas fuera de la provincia, generalmente a Quito, desvalorizando en un gran porcentaje la riqueza natural y cultural existente a nivel local.

Referente al abordaje de temáticas referentes a la conservación ambiental, los participantes señalan que formaron parte del proyecto TINI que es una propuesta pedagógica-ambiental que se da a través del programa de Educación Ambiental del Ministerio de Educación "La casa de todos". El proyecto es un espacio para cuidar el ambiente, proteger la biodiversidad 
y crear un ambiente de estudio limpio- Tini significa: "Tierra de niñas, niños y jóvenes para el buen vivir. Sus objetivos son: promover, comprometer y fortalecer la cultura y conciencia ambiental en la comunidad educativa. La pregunta ocho tiene relación a la muestra de interés de los niños por temas turísticos. Los docentes señalan que desde los minutos cívicos han promovido temas como el día del agua, fiesta del Inti Raymi y cuidado de los recursos. Los niños forman parte de esas actividades. La disposición de abordar la educación turística en el establecimiento es muy buena, ya que consideran que con la declaratoria de la provincia como geoparque es fundamental hacer algo, aportar con iniciativas e involucrar a todos los sectores productivos. Finalmente, en la pregunta diez, los participantes indican que establecer rutas donde se aborden sitios de interés es una alternativa muy buena, además visitar los sitios, involucrando material tecnológico como apoyo didáctico es importante, ya que se puede despertar en los estudiantes varias emociones, inclusive en la solución de conflictos que se les puede presentar en la vida cotidiana.

Por otro lado, se realizó una encuesta a los docentes de EGB correspondientes a quintos, sextos y séptimos grados. Se plantean trece preguntas con los siguientes criterios: muy de acuerdo, de acuerdo y en desacuerdo. Los resultados de la primera pregunta: La temática turística ha sido abordada en la Unidad Educativa, el 69,2\% de encuestados señala que está de acuerdo; un 15,4\% manifiesta que está muy de acuerdo; por otro lado, el 46,1\% considera que se ha tratado temas relacionados a los atractivos naturales y manifestaciones culturales a nivel local en las materias de ciencias naturales y estudios sociales. Los docentes señalan que los niños sí han mostrado curiosidad o interés de conocer el patrimonio natural y cultural, con un criterio de acuerdo en un porcentaje del 53,9\%. Además, dentro de la Unidad Educativa sí se han realizado actividades correspondientes también a cuidado ambiental al estar inmersos dentro del proyecto TINI, esta pregunta tiene un porcentaje de 53,9\%. Además, con un porcentaje del $61,5 \%$ correspondiente al criterio de acuerdo se han incorporado dentro del plan de estudios actividades para fortalecer las costumbres y tradiciones de la ciudad, pues han sido abordadas líneas temáticas referente a esto en los minutos cívicos y en días festivos. Los docentes señalan que están muy de acuerdo con un porcentaje de 53,9\% referente a la realización de eventos donde se ponga en valor la danza y música de la provincia de Imbabura. El 76, 9\% está muy de acuerdo en la necesidad de instruir a los niños y niñas en temas de educación turística. El 53,9\% de los docentes encuestados señalan que la mejor alternativa para formar al estudiante en temas turísticos es en el aula y en el entorno.

El $61,5 \%$ considera que es importante que los niños y niñas tengan actitudes y aptitudes sobre los espacios naturales y culturales que hay en la ciudad y la provincia. El 69,2\% señala 
que la institución educativa posee limitantes para abordar el tema de educación turística, entre las que se encuentran el desconocimiento por parte de ellos mismos referentes a Geoparque Imbabura e inclusive la manera de abordar la importancia de los geositios, fiestas, leyendas, tradiciones, música, danza. El 53,9\% señalan un interés alto de la comunidad educativa respecto al tema de educación turística, pues, el 69,2\% están de acuerdo en usar una guía con temáticas turísticas como soporte didáctico para el desarrollo de su actividad docente.

Una población de 126 estudiantes se ha tomado en cuenta para la aplicación de una encuesta con ocho preguntas, correspondientes a los sextos años de EGB distribuidos en cuatro paralelos. Las posibles respuestas giran en torno a tres criterios: sí, no y un poco. La primera interrogante es acerca del conocimiento que tienen sobre el turismo. El 85,7\% manifestó que sí conoce este término, asociándolo con actividades de descanso y con viajes fuera de donde viven, mientras que el $12,7 \%$ señala conocer un poco sobre turismo y un porcentaje menor correspondiente al $1,6 \%$ no conoce nada sobre la temática.

Con respecto a la segunda interrogante sobre si han escuchado algo acerca de geoparque Imbabura, el 65,1\% señala que no han escuchado nada acerca de esta declaratoria, el 22,2 $\%$ manifestó que sí conocen sobre el tema y el 12, 7 \% manifiesta saber un poco acerca de geoparque. La tercera pregunta planteada es: si en alguna de las asignaturas les enseñan sobre las costumbres y fiestas de la provincia de Imbabura; el 88,9\% señaló que en ciencias naturales, lengua y literatura y estudios sociales se han abordado estos aspectos; el 10,3\% considera que estos temas han sido tratados un poco en sus asignaturas. Por otro lado, en la cuarta pregunta referente al interés por conocer la historia de los sitios naturales y la cultura de la provincia de Imbabura, el 97,6 \% de los estudiantes encuestados señala que sí quieren saber sobre estos elementos. $Y$ a la quinta interrogante enfocada a si le gustaría conocer sobre el patrimonio natural de la provincia, el 96,8\% respondió de manera positiva. La sexta pregunta planteaba es si les gustaría conocer sobre el aspecto cultural, el $97,6 \%$ de estudiantes sí quiere saber sobre este tema. Se planteó la séptima pregunta referente a la realización de paseos o giras de observación alrededor de la provincia de Imbabura. El 74,6\% señalan que sí han realizado estas giras a nivel local y el 19,8\% respondió negativamente. Además, se escogieron doce geositios entre lagunas, termas y valles localizados en los diferentes cantones de la provincia para saber cuáles de esos lugares eran conocidos por los estudiantes. Los resultados son los siguientes: La laguna de Yahuarcocha que es uno de los principales atractivos turísticos del cantón lbarra obtiene un porcentaje mayoritario, pues el 96\% de los encuestados conocen el lugar. El Bosque Protector Guayabillas localizado en la ciudad de Ibarra ocupa el segundo lugar en ser conocido con un porcentaje de $71,4 \%$. A nivel 
de termas, las de Chachimbiro son conocidas por el 69,8\% de estudiantes; las menos conocidas son las termas de Nangulví del cantón Cotaccahi y Timbuyacu del cantón Urcuquí representadas por el 11, 9\% y 8,7\% respectivamente. La Cascada de Peguche perteneciente al cantón Otavalo tiene un porcentaje mayoritario en ser conocida por el 61,9\% de estudiantes. La Laguna de Cuicocha ubicada en el cantón Cotacachi es conocida por el $46 \%$ de encuestados mientras que la laguna de San Pablo localizada en el cantón Otavalo tiene un porcentaje de $42,1 \%$; la laguna menos identificada es la de Mojanda con un porcentaje de 11,9\%. Entre zonas rurales con sitios de interés se encuentran: Zuleta; la más conocida por el $45,4 \%$ de estudiantes; La Esperanza y el Valle del Chota, representadas con el $44,4 \%$ y $34,9 \%$ respectivamente.

Para el desarrollo de la investigación se ha tomado en cuenta también el criterio de los padres de familia, con una población de 126 personas. Son ocho preguntas elaboradas con tres criterios: sí, un poco y no. Los resultados obtenidos son los siguientes: El 49\% señala haber escuchado alguna vez sobre el término de educación turística, el 34\% no conoce sobre el tema y el $17 \%$ conoce un poco. Respecto a la segunda interrogante el $40 \%$ señala que sí tiene conocimiento acerca del término turismo, el 30\% manifiesta saber un poco. Por otro lado, el $63 \%$ manifiesta tener conocimiento sobre la relación de la actividad turística con aspectos ambientales, sociales y culturales. Un 19\% conoce un poco sobre el vínculo entre el turismo con estos componentes. En la cuarta pregunta planteada el $57 \%$ de encuestados respondió que sí han escuchado sobre la declaratoria de la provincia de Imbabura como Geoparque, mientras el 33\% no conoce acerca del tema. Además, el $90 \%$ señala que sí han visitado sitios naturales de la provincia de Imbabura. El $83 \%$ señaló que sí conocen algunos sitios turísticos de la ciudad de lbarra. Por otro lado, el 62\% señala de manera afirmativa su conocimiento sobre las costumbres y tradiciones a nivel local; el $32 \%$ sabe un poco y un porcentaje menor del $6 \%$ no conoce nada acerca del tema. El $90 \%$ de encuestados manifiesta que sí consideran importante fomentar educación en turismo en sus hijos dentro de la Unidad Educativa.

Para dar respuesta al tercer objetivo, se utiliza una ficha técnica donde se establecen contenidos turísticos de importancia en el contexto de Geoparque Imbabura y las metodologías para el uso de los docentes de sextos Años de Educación General Básica.

Cuadro 6. Propuesta de contenidos turísticos para abordar en las asignaturas

\begin{tabular}{cccl}
\hline & \multicolumn{3}{c}{ Área: Ciencias Naturales } \\
\hline Componentes & Objetivos & Contenidos & Estrategias didácticas \\
\hline Vida natural: & Identificar las & -Introducción a & -Revisión de información escrita sobre el \\
Flora y fauna & especies de & conceptos: flora & tema \\
& flora y fauna & y fauna &
\end{tabular}

ISSN: 1390-9320, Edición Especial, diciembre 2019 


$\begin{array}{ccc}\text { de mi } & \text { existentes en los } & \text {-Contraste de } \\ \text { provincia } & \text { páramos y } & \text { especies entre } \\ \text { valles. } & \text { ecosistemas }\end{array}$

-Observación de fotografías de flora y fauna a nivel de páramos y valles de la provincia

-Elaborar un organizador gráfico sobre las especies de fauna de páramos y valles -Dibujar una especie de flora propia de páramo y otra del valle

-Crear un álbum de cromos con fotografías de especies.

\begin{tabular}{|c|c|c|c|}
\hline $\begin{array}{c}\text { Conociendo } \\
\text { los climas de } \\
\text { mi provincia }\end{array}$ & $\begin{array}{c}\text { Analizar los } \\
\text { pisos climáticos } \\
\text { de Imbabura }\end{array}$ & $\begin{array}{l}\text { El clima como } \\
\text { un elemento } \\
\text { vital para el } \\
\text { desarrollo de la } \\
\text { vida } \\
\text {-Características } \\
\text { de los climas: } \\
\text { templado, frío, } \\
\text { cálido y páramo } \\
\text {-Climas } \\
\text { identificados en } \\
\text { los sitios } \\
\text { turísticos que } \\
\text { han visitado los } \\
\text { estudiantes }\end{array}$ & $\begin{array}{l}\text {-Observación de videos acerca de las } \\
\text { características y diferencias de los climas: } \\
\text { templado, cálido, frío y páramo } \\
\text { - Mesa redonda donde cada estudiante } \\
\text { indique los tipos de climas en los lugares } \\
\text { turísticos que han visitado. }\end{array}$ \\
\hline Componentes & Objetivos & Contenidos & Estrategias didácticas \\
\hline $\begin{array}{l}\text { Geoparque } \\
\text { Imbabura y } \\
\text { sus } \\
\text { dimensiones }\end{array}$ & $\begin{array}{l}\text { Socializar la } \\
\text { importancia de } \\
\text { la declaratoria } \\
\text { de Imbabura } \\
\text { como } \\
\text { geoparque } \\
\text { mundial }\end{array}$ & $\begin{array}{l}\text {-Concepto de } \\
\text { geoparque y su } \\
\text { importancia a } \\
\text { nivel nacional y } \\
\text { regional } \\
\text {-Análisis de las } \\
\text { dimensiones de } \\
\text { geoparque: } \\
\text { Conservación, } \\
\text { geoturismo y } \\
\text { educación }\end{array}$ & $\begin{array}{l}\text {-Elaborar un mural sobre la percepción } \\
\text { que los niños tienen acerca de geoparque. } \\
\text {-Mesa de debate: Los estudiantes aportan } \\
\text { con sus ideas sobre temas de } \\
\text { conservación y turismo. }\end{array}$ \\
\hline $\begin{array}{l}\text { Aprendiendo } \\
\text { sobre } \\
\text { geoturismo }\end{array}$ & $\begin{array}{l}\text { Analizar el } \\
\text { término de } \\
\text { geoturismo y su } \\
\text { vinculación con } \\
\text { el desarrollo } \\
\text { local }\end{array}$ & $\begin{array}{l}\text {-Importancia del } \\
\text { geoturismo a } \\
\text { nivel local } \\
\text {-Vinculando al } \\
\text { estudiante en el } \\
\text { fomento de } \\
\text { cultura turística }\end{array}$ & $\begin{array}{l}\text {-Observación de un video acerca de } \\
\text { Imbabura como Geoparque mundial } \\
\text {-Compartir experiencias sobre el } \\
\text { conocimiento que tienen de los lugares } \\
\text { turísticos que han visitado } \\
\text {-Lluvia de ideas acerca de la atención en } \\
\text { los diferentes servicios: alimentación, } \\
\text { recreación, hospedaje y transporte }\end{array}$ \\
\hline $\begin{array}{l}\text { Geografía de } \\
\text { mi provincia }\end{array}$ & $\begin{array}{l}\text { Identificar } \\
\text { aspectos } \\
\text { geográficos de } \\
\text { la provincia de } \\
\text { Imbabura }\end{array}$ & $\begin{array}{l}\text {-Ubicación de la } \\
\text { provincia de } \\
\text { Imbabura en el } \\
\text { Ecuador. } \\
\text {-Aspectos } \\
\text { territoriales, } \\
\text { cantones y } \\
\text { parroquias de la } \\
\text { provincia }\end{array}$ & $\begin{array}{l}\text {-Observar láminas educativas sobre } \\
\text { límites y ubicación de la provincia de } \\
\text { Imbabura en el mapa de Ecuador. } \\
\text {-Organizador gráfico en el que cada } \\
\text { estudiante señale lo que conoce sobre la } \\
\text { parroquia y el cantón en donde viven }\end{array}$ \\
\hline $\begin{array}{l}\text { Educación y } \\
\text { Patrimonio } \\
\text { cultural }\end{array}$ & $\begin{array}{l}\text { Analizar la } \\
\text { relación } \\
\text { existente entre } \\
\text { educación y }\end{array}$ & $\begin{array}{l}\text {-Concepto e } \\
\text { importancia del } \\
\text { patrimonio } \\
\text { cultural }\end{array}$ & $\begin{array}{l}\text {-Lluvia de ideas para analizar lo que los } \\
\text { estudiantes saben sobre cultura. } \\
\text { - Mesa redonda en la que el niño } \\
\text { comparta sus experiencias sobre visitas a } \\
\text { centros históricos de los cantones }\end{array}$ \\
\hline
\end{tabular}




\begin{tabular}{|c|c|c|c|}
\hline & $\begin{array}{l}\text { patrimonio } \\
\text { cultural }\end{array}$ & $\begin{array}{l}\text {-Sitios culturales } \\
\text { identificados por } \\
\text { los estudiantes }\end{array}$ & \\
\hline $\begin{array}{l}\text { Diversidad de } \\
\text { grupos étnicos } \\
\text { en mi } \\
\text { provincia }\end{array}$ & $\begin{array}{l}\text { Reconocer los } \\
\text { grupos étnicos } \\
\text { que existen en } \\
\text { la provincia de } \\
\text { Imbabura, } \\
\text { estableciendo } \\
\text { diferencias }\end{array}$ & $\begin{array}{l}\text {-Conociendo las } \\
\text { etnias de mi } \\
\text { provincia; } \\
\text { características de } \\
\text { los pueblos: } \\
\text { Cayambis, } \\
\text { Caranquis, } \\
\text { Otavalos, } \\
\text { Zuletas, } \\
\text { Natabuelas, } \\
\text { Afroecuatorianos, } \\
\text { Awas y } \\
\text { Montubios } \\
\text {-Territorios que } \\
\text { ocupan los } \\
\text { diferentes grupos } \\
\text { étnicos }\end{array}$ & $\begin{array}{l}\text {-Autoidentificación: cada niño define su } \\
\text { etnia. } \\
\text {-Observación de videos acerca de los } \\
\text { grupos étnicos de la provincia. } \\
\text {-Presentación de fotografías en la que los } \\
\text { estudiantes definan la etnia partiendo de } \\
\text { las características y vestimenta que se } \\
\text { muestren. } \\
\text {-Delimitar en un mapa el territorio que } \\
\text { ocupa cada etnia }\end{array}$ \\
\hline $\begin{array}{l}\text { Costumbres y } \\
\text { tradiciones }\end{array}$ & $\begin{array}{l}\text { Revalorizar las } \\
\text { costumbres y } \\
\text { tradiciones } \\
\text { existentes a } \\
\text { nivel de la } \\
\text { provincia }\end{array}$ & $\begin{array}{l}\text {-Concepto de } \\
\text { costumbre y } \\
\text { tradición } \\
\text {-Fiestas } \\
\text { tradicionales a } \\
\text { nivel de la } \\
\text { provincia } \\
\text {-Gastronomía } \\
\text { típica de cada } \\
\text { cantón }\end{array}$ & $\begin{array}{l}\text {-Focus group en el que los estudiantes } \\
\text { señalen las fiestas tradicionales que } \\
\text { conocen } \\
\text {-Observar videos sobre fiestas y } \\
\text { costumbres de los diferentes grupos } \\
\text { étnicos } \\
\text {-Feria gastronómica en cada aula en el } \\
\text { que se haga una degustación de comida } \\
\text { típica a nivel de la provincia. }\end{array}$ \\
\hline & & Área: Lengua y & eratura \\
\hline Componentes & Objetivos & Contenidos & Estrategias didácticas \\
\hline $\begin{array}{l}\text { Toponimia de } \\
\text { geositios de la } \\
\text { provincia de } \\
\text { Imbabura }\end{array}$ & $\begin{array}{l}\text { Socializar la } \\
\text { importancia de } \\
\text { la declaratoria } \\
\text { de Imbabura } \\
\text { como } \\
\text { geoparque } \\
\text { mundial }\end{array}$ & $\begin{array}{l}\text {-Origen y } \\
\text { significado de los } \\
\text { nombres de los } \\
\text { cantones de la } \\
\text { provincia } \\
\text {-Sitios turísticos } \\
\text { de la provincia y } \\
\text { su significado }\end{array}$ & $\begin{array}{l}\text {-Análisis y control de lecturas sobre el } \\
\text { significado de nombres de los cantones. } \\
\text {-Revisión bibliográfica en grupos de } \\
\text { trabajo sobre los Idiomas de los que } \\
\text { provienen los nombres de los cantones }\end{array}$ \\
\hline $\begin{array}{l}\text { Cuentos y } \\
\text { leyendas de } \\
\text { mi tierra }\end{array}$ & $\begin{array}{l}\text { Conocer los } \\
\text { cuentos y } \\
\text { leyendas } \\
\text { tradicionales de } \\
\text { los cantones }\end{array}$ & $\begin{array}{l}\text {-Concepto de } \\
\text { cuentos y } \\
\text { leyendas } \\
\text {-Leyendas } \\
\text { tradicionales a } \\
\text { nivel local }\end{array}$ & $\begin{array}{l}\text {-Dramatización corta sobre una leyenda } \\
\text { típica en grupos de trabajo } \\
\text {-Promover la creatividad en la que el } \\
\text { estudiante realice un cuento corto acerca } \\
\text { de un lugar turístico que conozca. }\end{array}$ \\
\hline $\begin{array}{l}\text { Sabiduría } \\
\text { popular, un } \\
\text { legado } \\
\text { ancestral }\end{array}$ & $\begin{array}{l}\text { Identificar los } \\
\text { idiomas y la } \\
\text { música de los } \\
\text { grupos étnicos } \\
\text { de la provincia } \\
\text { de Imbabura }\end{array}$ & $\begin{array}{l}\text {-Idiomas de los } \\
\text { grupos étnicos y } \\
\text { su contraste } \\
\text {-Música: } \\
\text { Folklórica, la } \\
\text { Bomba y sus } \\
\text { instrumentos }\end{array}$ & $\begin{array}{l}\text {-Revisión bibliográfica sobre idiomas, } \\
\text { seguimiento de un taller de lectura } \\
\text {-Observación de videos sobre grupos } \\
\text { musicales reconocidos de la provincia }\end{array}$ \\
\hline \multicolumn{4}{|c|}{ Área: Matemática } \\
\hline Componentes & Objetivos & Contenidos & Estrategias didácticas \\
\hline
\end{tabular}




\begin{tabular}{|c|c|c|c|}
\hline $\begin{array}{l}\text { Diversidad de } \\
\text { ecosistemas } \\
\text { en un territorio } \\
\text { pequeño }\end{array}$ & $\begin{array}{l}\text { Establecer los } \\
\text { tipos de } \\
\text { ecosistemas en } \\
\text { la provincia }\end{array}$ & $\begin{array}{l}\text {-Concepto de } \\
\text { ecosistemas } \\
\text {-Características } \\
\text { de los } \\
\text { ecosistemas } \\
\text { (terrestre, } \\
\text { montañoso, } \\
\text { marino, forestal) }\end{array}$ & $\begin{array}{l}\text {-Revisión bibliográfica sobre los } \\
\text { ecosistemas, talleres de control de lectura } \\
\text {-Exposición en carteles sobre las } \\
\text { diferencias entre cada ecosistema }\end{array}$ \\
\hline $\begin{array}{l}\text { Patrimonio } \\
\text { natural de mi } \\
\text { tierra }\end{array}$ & $\begin{array}{l}\text { Identificar los } \\
\text { sitios naturales } \\
\text { considerados } \\
\text { como geositios } \\
\text { turísticos de la } \\
\text { provincia }\end{array}$ & $\begin{array}{l}\text {-Concepto de } \\
\text { patrimonio y su } \\
\text { importancia } \\
\text {-Concepto de } \\
\text { geositio } \\
\text {-Revisión de } \\
\text { geositios de los } \\
\text { cantones de la } \\
\text { provincia }\end{array}$ & $\begin{array}{l}\text {-Taller fotográfico: los estudiantes } \\
\text { observarán imágenes sobre lugares } \\
\text { naturales que han sido denominados como } \\
\text { geositios } \\
\text {-Observar videos sobre los sitios naturales } \\
\text { de cada cantón de la provincia. }\end{array}$ \\
\hline $\begin{array}{l}\text { Conservando } \\
\text { los recursos } \\
\text { naturales }\end{array}$ & $\begin{array}{l}\text { Promover el } \\
\text { cuidado de los } \\
\text { recursos } \\
\text { naturales de la } \\
\text { provincia }\end{array}$ & $\begin{array}{l}\text { - ¿Cómo cuidar } \\
\text { el agua en los } \\
\text { lugares que } \\
\text { visito? } \\
\text {-Manejo de } \\
\text { desechos } \\
\text { orgánicos e } \\
\text { inorgánicos en } \\
\text { los lugares que } \\
\text { visito }\end{array}$ & $\begin{array}{l}\text {-Reflexionar sobre la importancia de } \\
\text { proteger los recursos naturales mediante la } \\
\text { observación de un video } \\
\text {-Presentar fotografías acerca del aporte } \\
\text { que ellos pueden generar al cuidado } \\
\text { ambiental con el buen manejo de } \\
\text { desechos. }\end{array}$ \\
\hline \multicolumn{4}{|c|}{ Área: Estudios Sociales } \\
\hline $\begin{array}{l}\text { Estadísticas } \\
\text { Poblacionales }\end{array}$ & $\begin{array}{l}\text { Determinar } \\
\text { cifras acerca de } \\
\text { la población } \\
\text { existente en los } \\
\text { cantones de la } \\
\text { provincia }\end{array}$ & $\begin{array}{l}\text {-Concepto e } \\
\text { importancia de la } \\
\text { estadística } \\
\text {-Cantidad de } \\
\text { habitantes } \\
\text { distribuidos en } \\
\text { los cantones: } \\
\text { lbarra, Otavalo, } \\
\text { Antonio Ante, } \\
\text { Urcuquí, } \\
\text { Cotacachi y } \\
\text { Pimampiro }\end{array}$ & $\begin{array}{l}\text {-Revisión bibliográfica en bases de datos } \\
\text { nacionales } \\
\text { - Juego de carreras de obstáculos con } \\
\text { cantidades numéricas }\end{array}$ \\
\hline $\begin{array}{l}\text { Sitios } \\
\text { turísticos de } \\
\text { mi provincia }\end{array}$ & $\begin{array}{l}\text { Establecer los } \\
\text { sitios turísticos } \\
\text { conocidos por } \\
\text { los estudiantes }\end{array}$ & $\begin{array}{l}\text {-Listado de } \\
\text { lugares turísticos } \\
\text { que conocen los } \\
\text { estudiantes } \\
\text {-Enumerar los } \\
\text { sitios naturales y } \\
\text { culturales } \\
\text { identificados }\end{array}$ & $\begin{array}{l}\text {-Realizar una rueda numérica en la que se } \\
\text { establezcan los sitios turísticos con } \\
\text { fotografías } \\
\text {-Establecer una figura por lugares } \\
\text { naturales y culturales para realizar } \\
\text { sumatorias. }\end{array}$ \\
\hline
\end{tabular}

Fuente: Elaboración propia. 


\section{CONCLUSIONES}

Se identificaron las materias, contenidos y metodologías por unidades didácticas respecto a la educación turística existentes en los planes de estudios actuales de los sextos años de EGB, estableciendo que en las materias de ciencias naturales y estudios sociales se abordan temas referentes a historia, cultura, ecosistemas, nacionalidades, a nivel nacional. Sin embargo, no se ha tratado el tema turístico de manera objetiva.

Se determinó la disposición de la comunidad educativa para involucrarse en el tema de educación turística en el contexto Geoparque Imbabura, donde autoridades, docentes, padres de familia y estudiantes emitieron un criterio respecto al conocimiento acerca de esta declaratoria, además mostraron un interés alto en fomentar educación turística en la institución abordando temáticas que permitan formar al estudiante en valores e incrementar su nivel de aprendizaje acerca del patrimonio natural y cultural de la provincia.

Se diseñó una guía con temáticas turísticas de importancia en el contexto de Geoparque Imbabura como material de apoyo didáctico para los docentes de sextos años de EGB en la que se establecieron: componentes, objetivos, contenidos y estrategias didácticas para las asignaturas elementales.

\section{REFERENCIAS BIBLIOGRÁFICAS}

Cazares, W., Aranguren, J., y Moncada, J. (septiembre de 2017). Educación para el turismo sustentable en la escuela ecuatoriana. Una propuesta para la parroquia La Libertad, cantón Espejo, provincia del Carchi. Revista de Investigación (92), 34-55.

Colom, A. y Brown, G. (1993). Turismo y educación: bases para una pedagogía del turismo. Revista Española de Pedagogía, enero-abril 1993, Valencia, España

Constitución del Ecuador (2008). Principios de la Educación.

Convención sobre la protección del patrimonio mundial, cultural y natural (1972). Artículo 27, educación patrimonial.

Díaz, A., y Machado, R. (2016). La formación en cultura turística en instituciones educativas: Un aporte del programa "Colegios amigos del Turismo" en Colombia. Rey, turismo y Sociedad, XIX, 49-71. 
Farsani, N.T; Coelho, C.; Costa, C.; Carvalho, C.N. Geoparks \& Geotourism: New approaches to sustainability for the 21st century. Boca Raton: Brown Walker Press, 2012.

INEC (2010). Población y demografía de la provincia de Imbabura.

Kolv, D (s.f). Ciclo de Aprendizaje ERCA, Didáctica en el uso de recursos. Recuperado de https://didactica.wordpress.com/f/

Ministerio de Educación (2016). Guía introductoria a la metodología TINI. Asociación para la niñez y su ambiente ANIA.

Ministerio de Educación (2018). Nueva Malla curricular 2019-2020. Educación General Básica para los subniveles de Preparatoria, Elemental, Media y Superior.

Junta Académica. (2019). Ideario, Misión y Visión Institucionales. Ibarra.

Ley Orgánica de Cultura. Diciembre 2016. Editora Nacional del Ecuador.

LOEI. (2019). Marco Legal Educativo. Ecuador.

Proyecto Geoparque Imbabura (2015). Descripción y Geografía de la provincia.

Ramón, A., \& Fernández, G. (2016). Geoconservación, Geoturismo Y Espeleoturismo:

Análisis de dos sistemas cavernarios en Argentina. Pesquisas em Turismo e Paisagens Cársticas, 83-93.

Red Global de Geoparques (2011). Concepto de Geoparque.

Tamayo Salcedo, A. L., y Peñaloza Suárez, L. (2005). Investigación en turismo y educación en la Universidad Autónoma del Estado de México. Teoría y Praxis, 87-95.

Unesco (2015). Objetivos de Desarrollo Sostenible -ODS- y 167 metas para 2030.

Unidad Educativa Luis Leoro Franco (2018). Plan curricular institucional 2018-2022.

Unidad Educativa Luis Leoro Franco (2019). Plan curricular anual de sextos años de educación general básica. (PCA).

Unidad Educativa Luis Leoro Franco (2019). Plan de unidades didácticas de sextos años de educación general básica. (PUD). 